\title{
Universiteit
}

Leiden

The Netherlands

\section{A nationwide cross-sectional survey of pharmacy students on pharmacogenetic testing in The Netherlands}

Bank, P.C.D.; Swen, J.J.; Guchelaar, H.J.

\section{Citation}

Bank, P. C. D., Swen, J. J., \& Guchelaar, H. J. (2018). A nationwide cross-sectional survey of pharmacy students on pharmacogenetic testing in The Netherlands. Pharmacogenomics, 19(4), 311-319. doi:10.2217/pgs-2017-0175

Version: $\quad$ Not Applicable (or Unknown)

License: $\quad$ Leiden University Non-exclusive license

Downloaded from: https://hdl.handle.net/1887/77649

Note: To cite this publication please use the final published version (if applicable). 


\begin{abstract}
To benchmark knowledge and attitude of pharmacy students towards pharmacogenetics (PGx) and PGxtesting and compare the results to practicing colleagues. All pharmacy students in The Netherlands were invited to participate in a web-based survey consisting of 28 questions.Of the 824 invited students, 148 individuals (18.0\%) completed the questionnaire. All responders believed in the concept of PGx and had high expectations towards PGx. The majority (96.6\%) had received some form of education on PGx, but only $12.8 \%$ felt adequately informed. When compared to practicing pharmacists' differences were observed in the use of information and feeling qualified to recommend PGx-testing. More education on PGx is required in the curriculum to fill the perceived knowledge gap among future pharmacists.
\end{abstract}




\section{Introduction}

In recent years the field of pharmacogenetics (PGx) has developed rapidly and this has translated to an increasing number of drug labels containing information on genetic biomarkers $(1,2)$. In addition, the Clinical Pharmacogenetics Implementation Consortium (CPIC) and the Dutch Pharmacogenetics Working Group (DPWG) have created widely recognized guidelines with therapeutic recommendations for patients with a known genotype (3-5). Consequently, healthcare professionals need to develop their knowledge of pharmacogenetics to be able to optimize patient care based on pharmacogenetic markers. Previous studies have shown that physicians and pharmacists in the United States, Canada and the Netherlands have high expectations of PGx to improve the efficacy and safety of drugs. However, despite the enthusiasm of physicians and pharmacists towards PGx, a knowledge gap on this subject appears to be present (6-8). This knowledge gap potentially hinders the adoption of PGx into clinical care and may be the consequence of a lack of education on PGx in their curriculum (8). To solve the lack of knowledge among healthcare professionals additional PGx related education could be essential. Pharmacy students represent the next generation of pharmacists and are bound to come into contact with the field of PGx in their later career path. Limited knowledge among these students may impede PGx application in clinical care. In a statement issued in 2015 the American Society of Health-System Pharmacists has encouraged the embedding of education on PGx in college of pharmacy curricula and Specialties certification programs (9). In the Netherlands The Royal Dutch Pharmacist's Association (KNMP) has incorporated PGx in their view of the future for care in 2020, but no clear recommendation to incorporate PGx in the pharmacy curricula (see box 1) exist (10).

Currently, it is unknown whether pharmacy students receive education on PGx and what their expectations and attitudes of pharmacy students towards PGx and PGx-testing are. In this study we set out to investigate whether pharmacy students believe in the concept of PGx, what expectations they have towards PGx, to research whether a knowledge gap on PGx is present among these students and to analyse whether there are differences between pharmacy students and practising pharmacists. 


\section{Methods}

\section{Study design}

Similar to a previous survey of practicing pharmacists, a web-based survey was performed with NetQ [101]. In brief, a list with the email addresses of all students of pharmacy in The Netherlands was obtained from the KNMP and an email with a link to the survey was sent to 824 students. After two weeks a reminder was sent. The students could complete the survey between December $15^{\text {th }} 2014$ and February $1^{\text {st }} 2015$. Participation was completely voluntary and no reimbursement was offered. All responses were analysed anonymously. For the comparison with Dutch practicing pharmacists the results of a cohort of 667 pharmacists that completed an identical set of the questions (see below) were used (8).

\section{Questionnaire}

A questionnaire previously described in detail was used (6-8). Questions not applicable for students were removed (e.g. questions relating to PGx tests ordered or recommended in a clinical setting). In the first part of the survey a brief overview of the topics covered and an explanation for pharmacogenetics was provided. In total the questionnaire consisted of 28 questions divided among five sections. In the first section five questions were asked to gather baseline information on the participants. The second part of the questionnaire (Q6-9) surveyed the responders' belief in the concept of PGx and their expectations towards PGx. In the third section (Q10-13) participants were asked questions relating to attitudes of toward their own abilities. Q14-20 (section 4) surveyed sources of information of PGx used by candidates. In the final section (Q1-28) of the survey the participants were asked questions relating to ethics and test coverage (see supplementary document 1 ).

\section{Survey Analysis}

Survey responses were automatically tabulated and stored by Netq. For the analysis of the responses only complete questionnaires were included. In order to compare the results of the pharmacy students with the previously surveyed pharmacists age was recoded in a six-level categorical variable $(\leq 29,30-39,40-49$, $50-59, \geq 60$ years) and the answers of Q17 (see supplementary document 1 ) were condensed to a three level variable ((very) unimportant, undecided, (very) important) (8). The $\chi^{2}$ test was used to test for 
univariate associations. Binary logistic regression, multinomial logistic regression and ordinal logistic regression were used for the multivariate analyses using gender and age-groups as covariates. For the analysis of question 12 (see supplementary document 1) age was condensed from a six-level to a fivelevel categorical variable ( $\leq 29,30-39,40-49, \geq 50$ years). Statistical analyses were performed with SPSS version 20 (SPSS, Inc., Illinois, USA) with $\mathrm{p}<0.05$ considered significant.

\section{Results}

\section{Characterization of responders}

Out of the 824 pharmacy students who received an invitation to participate in the survey 148 students $(18.0 \%)$ completed the questionnaire. Of the responders $70.3 \%$ was female and the median age was 24 .

The survey included students from the second through the sixth year of the study with a large majority of the responders being master students (93.9\%). Of the students $96.6 \%$ had received some education in PGx as part of the curriculum.

\section{Belief in the concept of PGx \& expectations towards PGx(-testing)}

All students included in the analysis indicated to believe in the concept of (partially) hereditary drug response. To benchmark the expectation of the students towards PGx and PGx-testing they were asked to rate three statements on a scale from 0 (no expectation) to 3 (high expectation). To the question whether they expected a PGx test could prevent a patient from receiving the wrong choice of drug or dose of a given treatment $86.5 \%$ of the students scored at least 2. For the statements "I expect that a PGx test will detect the most efficacious drug or dose" and "I expect that a PGx test will allow for detection the drug or dose that will cause less side effects" $87.2 \%$ and $73.7 \%$ of the student rated with a score $\geq 2$ (see figure 1). 
Table 1: Characteristics of responders

\begin{tabular}{|c|c|c|}
\hline & $\mathrm{N}$ & $\%$ \\
\hline \multicolumn{3}{|l|}{ Gender } \\
\hline Male & 44 & 29.7 \\
\hline Female & 104 & 70.3 \\
\hline \multicolumn{3}{|l|}{ Age } \\
\hline 20 & 4 & 2.7 \\
\hline 21 & 11 & 7.4 \\
\hline 22 & 15 & 10.1 \\
\hline 23 & 30 & 20.3 \\
\hline 24 & 35 & 23.6 \\
\hline 25 & 31 & 20.9 \\
\hline 26 & 15 & 10.1 \\
\hline 27 & 1 & 0.7 \\
\hline 28 & 4 & 2.7 \\
\hline 29 & 2 & 1.4 \\
\hline \multicolumn{3}{|c|}{ In which year of the program do you currently follow courses? } \\
\hline Second Year & 1 & 0.7 \\
\hline Third Year & 8 & 5.4 \\
\hline Forth Year & 18.2 & 18.2 \\
\hline Fifth Year & 28.4 & 28.4 \\
\hline Sixth Year & 47.3 & 47.3 \\
\hline \multicolumn{3}{|c|}{ Has received education on PGx as part of their curriculum? } \\
\hline Yes & 143 & 96.6 \\
\hline No & 5 & 3.4 \\
\hline
\end{tabular}

Figure 1: Expectations of pharmacy students towards PGx testing

\section{Pharmacy students expect that a PGx test ...}

... will prevent a wrong drug / dose

...will detect the most efficacious drug / dose

... will cause less side effects of drug / dose
17

23

38
73

63

66

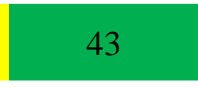

Red $=$ I have a very low expectation that PGx ..., orange $=$ I have a low expectation that PGx ..., yellow $=\mathrm{I}$ have a high expectation that PGx ..., green $=$ have a very high expectation that PGx ... (the size of the bar is proportional to the number of respondents) 


\section{Attitude towards own expected ability to interpret PGx test results}

Of the surveyed students $27.7 \%$ feels qualified to receive the PGx result of a patient, interpret genotype(s) and advise a treating healthcare professionals or patient on the choice of the drug regimen based on the results. The large majority (70.9\%) see themselves qualified to receive and interpret a genotype and advise a patient or colleague based on the results, but only after receiving additional training on the subject, while $1.4 \%$ does not think this is part of their (future) job description. $75.0 \%$ sees him/herself qualified to recommend PGx testing to patients if the PGx test can reveal whether a drug is effective, whereas $8.1 \%$ does not feel qualified and $16.9 \%$ does not know. If the PGx test could also reveal a disease the patient is susceptible to in the future $20.9 \%$ would feel qualified to recommend the test and $23.0 \%$ would feel qualified only if the disease could be treated. In contrast, $31.1 \%$ would not feel qualified to recommend a PGx test if that could reveal a disease and $25.0 \%$ does not know if they would feel qualified in that case. When a PGx test would reveal that the only available drug therapy for a patient will not work or would lead to severe side effects $31.1 \%$ of the surveyed student would not treat the patient with that drug and $64.2 \%$ would only give the treatment if the patient was suffering from a life-threatening condition. Only $4.7 \%$ of the responders would continue with the drug even though the results of the PGx would indicate no efficacy.

\section{Access to and use of PGx information}

Although $96.6 \%$ of the students indicated that they had received education on PGx only $12.8 \%$ of all students currently feels adequately informed about the availability of PGx-tests and how to apply PGx in treatment of patients. Among students in the final year of their curriculum $(n=) 17.1 \%$ of the responders felt adequately informed about PGx testing. $90.5 \%$ of the responders indicated they would use additional sources of information on how to apply PGx testing in pharmacotherapy of patients. The different sources of information used by students to obtain information about the use of PGx in relation to treatment or to support a choice in drug and dose in case of patient with an actionable phenotype predicted from a PGx test can be found in supplementary document 2 . 


\section{Worries related toward PGx testing, privacy \& coverage of PGx tests}

In the last section of the questionnaire the students were benchmarked on potential worries towards the results of PGx testing, privacy and insurance of the PGx tests. Similar to the assessment of the expectations the students were asked to rate four questions on a four point scale from very low worries $(0)$ to very high worries (3). To the question whether they were worried that a PGx might show that there is no suitable treatment for their patient $44.0 \%$ scored at least 2 . Slightly more students $(57.5 \%)$ were at least moderately worried (score $\geq 2$ ) that a PGx test could show that a patient carries additional risk factors for another disease. $71.7 \%$ scored a 2 or 3 on the question whether they were worried that PGx test results could fall in the hands of unauthorized individuals. Almost all of the surveyed students (91.2\%) were at least moderately worried that insurance companies could infer a patients genotype based on the drug or dose a patient is prescribed (see figure 2). Students also showed worries concerning the potential impact of unfortunate PGx test results, as $87.2 \%$ believed this could have negative psychological effects on the patients and their family. And $23.0 \%$ of the responders were more worried for loss of privacy of the results of a PGx test compared to other diagnostic or laboratory tests. In their opinion the treating physician (98.0\%) and pharmacist (99.3\%) should have access to PGx data, whereas only a small portion of the surveyed students thought psychologists (8.8\%), dieticians (4.7\%), nurses (3.4\%) and social workers $(1.4 \%)$ were allowed to access to results of PGx tests. Among the students there was no consensus on whether clinical geneticists (78.4\%), clinical chemist (43.2\%) or nurse-practitioners (16.9\%) should be allowed to see a patients' PGx-data. Finally, the students were asked if insurance companies should reimburse PGx-tests. All students were of the opinion that this indeed should be the case, but thought differently about the frequency in which PGx tests should be reimbursed. According to $78.4 \%$ of the students thought this should only be in certain occasions, whereas $21.6 \%$ thinks PGx tests should always be covered. 
Figure 2: worries of pharmacy students towards PGx testing

\section{Pharmacy students are worried that ...}

... a PGx test might show there is no suitable drug for
your patient

... a PGx test results could be passed to an unauthorized person

... a PGx test could reveal that your patient also has risk factors for another disease

... a health insurance could obtain information about an individual's genotype based on the drug/dose prescribed

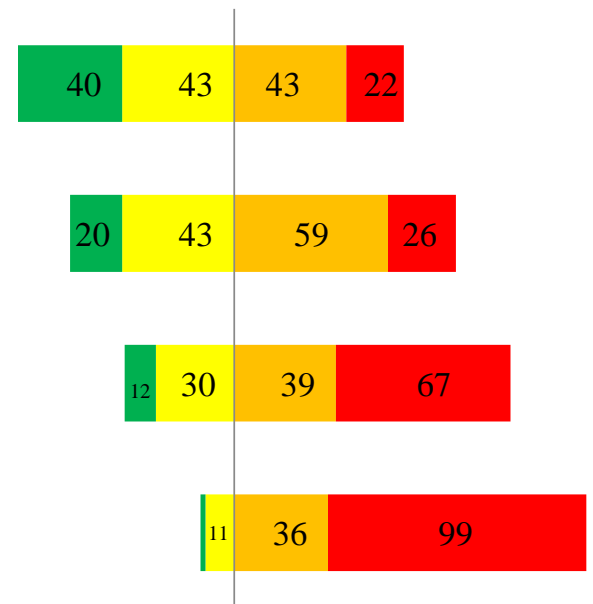

Green $=$ I have very low worries that $\ldots(0)$, yellow $=$ I have a low worries that $\ldots(1)$, orange $=\mathrm{I}$ have a high worries that PGx ... (2), red = have a very high worries that PGx ... (3)

(the size of the bar is proportional to the number of respondents)

\section{Differences between pharmacy students and practicing pharmacists}

In a secondary analysis the responses of the pharmacy students were compared to the results of a previous survey among practicing pharmacists. In the univariate analyses between the two groups differences could be observed in multiple questions. In comparison, practicing pharmacists more often felt that interpreting PGx test results and advise patients and other healthcare professionals based on genotypes was not part of their job description $(6.7 \%$ vs. $1.4 \%, \mathrm{p}=0.038)$. Additionally, practicing pharmacists less often felt qualified to recommend PGx testing to predict the efficacy of drug treatments (48.4\% vs. $75.0 \%, \mathrm{p}<$ 0.001) and less often felt qualified recommending a genetic test if that test could reveal information about a disease a patient was susceptible to $(7.8 \%$ vs. $20.9 \%, \mathrm{p}<0.001)$. Practicing pharmacists were more likely to stop a treatment if a PGx test would indicate if the only available drug was not effective or would lead to severe side-effects $(49.0 \%$ vs. $31.1 \%, \mathrm{p}<0.001)$.

Differences were also seen in the use of information sources on how to apply PGx testing in pharmacotherapy of patients. In general pharmacy students more often indicated to use additional sources 
of information to determine the application of PGx in relation to pharmacotherapy $(90.5 \%$ vs. $38.7 \%$, p < $0.001)$.

Pharmacy students more often believed that an unfavourable result from a PGx test could have negative psychological consequences on a patient and his/her family $(87.2 \%$ vs. $63.7 \%, \mathrm{p}=0.034)$ and were more often at least moderately worried that PGx could show that there is no suitable treatment for a patient (44.0\% vs. $28.3 \%$, p <0.001). Finally, a difference was observed in whether social workers should have access to PGx data, as pharmacy students more often agreed with this statement compared to practicing pharmacists $(1.4 \%$ vs. $0.1 \%, \mathrm{p}=0.029)$. In other questions no significant differences were visible in the univariate analysis (supplementary document 3). Using gender and age groups as co-variants the multivariate analysis revealed that pharmacy students more often would feel qualified to recommend PGx testing to predict drug efficacy (odd's ratio $(\mathrm{OR})=5,25$ (confidence interval $(\mathrm{CFI})=2,47-11,16, \mathrm{p}<$ 0.001), more often obtain extra information on genetic testing and its application in the context of drug therapy $(\mathrm{OR}=12,61(\mathrm{CFI}=6,42-24,77), \mathrm{p}<0,001)$ and more often think that an unfavourable test results could have adverse psychological consequences on him and his family $(\mathrm{OR}=2,92(1,08-7,89), \mathrm{p}$ $=0.034)$. In contrast, pharmacy students are less often aware of the incorporation of medication surveillance based on genotype in electronic drug dispensing systems $(\mathrm{OR}=0,12(0,07-0,22), \mathrm{p}<$ 0.001) (supplementary document 4).

\section{Discussion}

This study shows that pharmacy students believe in the concept of (partially) heritable drug response. The surveyed students had high expectations of PGx in making pharmacotherapy safer and more effective even though some concerns were also present among the responders of this survey. Despite almost all responders received some sort of education on PGx as part of their curriculum, the majority of students did not feel adequately informed about PGx. This effect remained visible in the responders who were in the last year of their education. Also worries that unauthorized individuals could obtain a patients' 
genotype or that insurance companies can infer a genotype from a prescribed dose or alternate choice of drug scored relatively high.

When the results of the pharmacy students are compared with the results of practicing pharmacists it can be seen that the results are quite similar although there are some differences. The differences between the students and their practicing colleagues are mainly present in feeling qualified to recommend PGx testing to predict efficacy of a specific drug, whether individuals would use additional information to support the use of PGx test in therapy, the sort of sources of information used to support PGx testing within therapy and the information sources to support changes in drug and dose in case of a known actionable genotype.. Differences in feeling qualified to recommend PGx to predict efficacy of a treatment may be explained by clinical experience gained in the field or a degree of selection bias in the previous survey where pharmacist who had adopted a PGx test (and as a result had more confidence in their abilities to recommend testing) were more likely to respond to the survey as they were familiar with the topic. The differences in use sources of information may be the result of an ideal situation in case of the student group vs. the actual situation in practice in the group of the pharmacists. Finally, differences in knowledge of the incorporation of medication surveillance in electronic medication surveillance systems may be explained by the fact that pharmacy students do have gained experiences using this form of clinical decision support in clinical practice.

In this cross-sectional study of pharmacy students were benchmarked to a number of PGx-related topics including expectations and worries towards PGx-testing. The expectations of the students seem to be generally high with over $80 \%$ of the students scoring at least $\geq 2$ prevent receiving a wrong regimen and predict which regimen is the most effective. Furthermore, $72.7 \%$ of the student scored at least $\geq 2$ on the same scale to rate their expectation that PGx will provide the ability to predict which regimen will give the lowest chance of side effects. In addition to similarities to Dutch practicing pharmacists the expectations benchmarked in this study are also comparable with a survey of Canadian pharmacists where 80.0, 82.6 and $79.1 \%$ scored moderately hopeful on the three statements respectively and the results of a 
survey of Jordanian pharmacists who also have similar high expectations of PGx in relation to pharmacotherapy $(7,8,11)$.

From table 1 it can be observed that $70.3 \%$ of the responders is female compared to $29.7 \%$ of male responders. In a previous study among Dutch pharmacists a (M:F) ratio of 45.\% 7: $54.3 \%$ was observed. Although this difference in male-female ratio can be interpreted as selection bias, the increase of females is in line with other research and likely a trend toward a more female profession (12). Additionally, as with any other questionnaire with no incentive for participating in the survey, there is risk for systematic bias as individuals with a strong opinion in both a positive or negative way are more likely to respond. In this survey the response rate among the pharmacy students was $18.0 \%$ which relatively high compared to previous surveys $(6,7)$. As a result of a relatively high response rate the risk of systematic bias in this study will be likely be low.

A striking finding in this survey is that only $12.8 \%$ of the students feel adequately informed about how to apply PGx in pharmacotherapy despite $96.6 \%$ of responders stating that PGx was part of their education which may result in a knowledge gap among future healthcare professionals. The percentage of students that felt adequately informed about PGx was similar to their older colleagues (14.1\%) of whom only $39.7 \%$ had received education as part of their curriculum (8). One explanation may be found in the manner in how information on PGx is integrated in the curriculum. At this moment information on PGx and its applicability in pharmacotherapy is still taught in a traditional form using lectures. If the current practising pharmacists had received any education as part of their curriculum, this was likely taught in a similar manner. With the decrease of the costs of sequencing it is anticipated that in the next years more and more patients will have a copy of their own genome. Pharmacogenetics is currently one of area's within genetics that is relatively easy to implement in the clinic. The healthcare professionals of tomorrow are bound to come in contact with PGx test results and should be able to interpret these results and use them to improve pharmacotherapy.

Although this survey identified a potential future knowledge gap among pharmacy students, the survey did not contain questions relating to the current implementation PGx in the curriculum (which year, which 
courses and credit hours etc.), the students' perception on the clinical utility of PGx, their views on how PGx should be implemented within the PharmD curriculum and potential outcomes of a structured PGx program. An assessment among 715 healthcare US students, including 328 pharmacy students, showed that $75.3 \%$ (strongly) agreed PGx should be an important part of the curriculum, whereas only $13.1 \%$ (strongly) agreed that PGx had indeed been an important part of the curriculum Furthermore, Adams et al. developed the "Test2Learn" program in which a cohort of pharmacy students underwent personal genomics testing and as a result gained confidence in understanding PGx test and increased their selfperceived ability to empathize with potential patients (13). Similarly, initiatives such as reported by Weitzel et al, in which students genotype themselves and use this hands on experience in an educational setting increases understanding of PGx testing and comfort levels of student regarding acting on PGx data (14). Additional research should investigate whether Dutch students also would like hands-on experience with PGx during the Dutch pharmacy program.

A similar elective course is present as a part of master Bio-Pharmaceutical Sciences at the Leiden University. In this course on clinical pharmacology students genotyped themselves, interpret their own genotypes and learn how to adjust medication based on their genetic predicted phenotype. A similar program as part of a course on medication surveillance could help pharmacy students with understanding the current state of field, the clinical utility of PGx and their ability to interpret and act on genetic data. Further studies should investigate whether this form of education and/or in combination with other methods such as specialized residencies can reduce the PGx knowledge gap in the current pharmacy curriculum.

\section{Conclusion}

This study shows that pharmacy students believe in the concept of hereditary drug response and have high expectations towards PGx. In a comparison with practicing pharmacists' differences in elements of feeling qualified to recommend PGx testing, the use of information on the applicability of PGx in pharmacotherapy and opinions about the possible negative impact of PGx tests were observed. Similar to 
their future colleagues the surveyed students perceive a knowledge gap despite having received education

on the subject.

\section{References}

1. Ehmann F, Caneva L, Prasad K, Paulmichl M, Maliepaard M, Llerena A, et al. Pharmacogenomic information in drug labels: European Medicines Agency perspective. Pharmacogenomics J. 2015;15(3):201-10.

2. Whirl-Carrillo M, McDonagh EM, Hebert JM, Gong L, Sangkuhl K, Thorn CF, et al. Pharmacogenomics knowledge for personalized medicine. Clin Pharmacol Ther. 2012;92(4):414-7.

3. Swen JJ, Nijenhuis M, de BA, Grandia L, AH M-vdZ, Mulder H, et al. Pharmacogenetics: from bench to byte--an update of guidelines. Clin Pharmacol Ther. 2011;89(5):662-73.

4. Swen JJ, Wilting I, de Goede AL, Grandia L, Mulder H, Touw DJ, et al. Pharmacogenetics: from bench to byte. Clin Pharmacol Ther. 2008;83(5):781-7.

5. Relling MV, Klein TE. CPIC: Clinical Pharmacogenetics Implementation Consortium of the Pharmacogenomics Research Network. Clin Pharmacol Ther. 2011;89(3):464-7.

6. Stanek EJ, Sanders CL, Taber KA, Khalid M, Patel A, Verbrugge RR, et al. Adoption of pharmacogenomic testing by US physicians: results of a nationwide survey. Clin Pharmacol Ther. 2012;91(3):450-8.

7. de Denus S, Letarte N, Hurlimann T, Lambert JP, Lavoie A, Robb L, et al. An evaluation of pharmacists' expectations towards pharmacogenomics. Pharmacogenomics. 2013;14(2):165-75.

8. Bank PC, Swen JJ, Guchelaar HJ. A nationwide survey of pharmacists' perception of pharmacogenetics in the context of a clinical decision support system containing pharmacogenetics dosing recommendations.

Pharmacogenomics. 2017;18(3):215-25.

9. ASHP statement on the pharmacist's role in clinical pharmacogenomics. Am J Health Syst Pharm. 2015;72(7):579-81.

10. KNMP. Your pharmacist in 2020. 2017.

11. AlEjielat R, Eijelat Z, Andrawes S, Mhaidat NM. An evaluation of the knowledge, opinions, expectations and concerns toward pharmacogenomics among Jordanian pharmacists. pharmacogenomics. 2016;13(2):11.

12. Stichting Farmaceutische Kengetallen. Openbaar apotheker wordt vrouwenberoep. Pharmaceutisch Weekblad. 2016;150(48).

13. Adams SM, Anderson KB, Coons JC, Smith RB, Meyer SM, Parker LS, et al. Advancing

Pharmacogenomics Education in the Core PharmD Curriculum through Student Personal Genomic Testing. American journal of pharmaceutical education. 2016;80(1):3.

14. Weitzel KW, Aquilante CL, Johnson S, Kisor DF, Empey PE. Educational strategies to enable expansion of pharmacogenomics-based care. Am J Health Syst Pharm. 2016;73(23):1986-98. 


\section{Supplementary document 1 - Questionnaire}

Questions

Answer options

Section 1: Baseline information

Q1: What is your gender?

$\square$ Male

$\square$ Female

Q2: What is your age?

$\cdots$

Q3: At which University do you currently follow your curriculum?

$\square$ University of Groningen

$\square$ University of Leiden

$\square$ University of Utrecht

$\square$ Other

Q4: In which year of the program do you currently follow courses?

$\square$ First year

$\square$ Second year

$\square$ Third year

$\square$ Fourth year

$\square$ Fifth year

$\square$ Sixth year \begin{tabular}{l|l}
\hline $\begin{array}{l}\text { Q5: Has PGx been part of any course that you have followed as part of your } \\
\text { curriculum }\end{array}$ & $\square$ Yes \\
\cline { 2 - 3 } & $\square$ No
\end{tabular}

Section 2: Belief and expectations towards PGx

Q6: Do you believe that a patient's genetic profile may influence his/her response to drug therapy?

$\square$ Yes

$\square$ No

Q7: Do you expect that pharmacogenetic testing will prevent your patient from $\quad \square 0$ taking the wrong medicine (or the wrong dose) $(0=$ no expectations... $/ 3=\square 1$

very high expectations ...)

$\square 2$

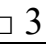

Q8: Do you expect that pharmacogenetic testing will allow detecting which drug (or which dose) will be more efficacious in your patient? $(0=$ no expectations.../3 = very high expectations ...)

\begin{tabular}{|l|l|}
$\square$ & 0 \\
\hline$\square 1$ \\
\hline$\square 2$ \\
\hline$\square 3$
\end{tabular}

Q9: Do you expect that pharmacogenetic testing will allow detecting which drug (or which dose) will cause less side effects in your patient? $(0=$ no expectations.../3 = very high expectations ...)

\begin{tabular}{|l|l|}
$\square 0$ \\
\hline$\square 1$ \\
\hline$\square 2$ \\
\hline$\square 3$
\end{tabular}


Section 3: Attitude towards own ability to interpret PGx test results Q10: Do you feel qualified to receive your patient's pharmacogenetic testing results, interpret them and advise your patient on a treatment choice?

$\square$ Yes

$\square$ Yes, but after having had training on the subject

$\square$ No, this is not my responsibility

Q11: Would you feel qualified to recommend pharmacogenetic testing to your patients if those tests could predict that a specific drug could be efficacious in

$\square$ Yes their case?

$\square$ No

$\square$ I don't know

Q12: If a pharmacogenetic test revealed that the only available drug to treat your patient's disease is ineffective or leads to severe side effects, would you still advise your patient to take that medicine?

$\square$ Yes

$\square$ No

$\square$ Yes, only if he/she had a lifethreatening disease

Q13: Would you feel qualified to recommend genetic testing to your patients if those tests could reveal which diseases are liable to affect them in the future

\begin{tabular}{|l}
$\square$ Yes \\
$\square$ Yes, but only if that disease \\
could be treated \\
\hline$\square$ No \\
\hline$\square$ I don't know \\
\hline
\end{tabular}

Section 4: Access to and use of PGx information

Q14: Do you feel that you are adequately informed about the availability of genetic testing and its application in the context of drug therapy?

$\square$ Yes

$\square$ No

Q15: Would you obtain extra information on genetic testing and its application in the context of drug therapy?

$\square$ Yes

$\square$ No

Q16: Where do you obtain information on genetic testing and its application in the context of drug therapy? (select all that apply)

$\square$ Drug labelling (package insert)

$\square$ Colleague

$\square$ Post-academic education and pharmacotherapeutic meetings

$\square$ Internet

$\square$ Genetic testing laboratory

$\square$ Other ...

Q17: What level of evidence is of importance to you in consideration of ordering a pharmacogenetic test

\begin{tabular}{|l|l|l|l|l|l|}
\hline $\begin{array}{l}\text { Authority approval or } \\
\text { recommendation }\end{array}$ & Very unimportant & Unimportant & Un-decided & Important & very important \\
\hline Speciality guideline & & & & & \\
\hline Scientific journal & & & & & \\
\hline $\begin{array}{l}\text { Recommendation or } \\
\text { experience of thought } \\
\text { leaders or respected } \\
\text { colleagues }\end{array}$ & & & & & \\
\hline
\end{tabular}


Q18: Where do you obtain information to make a choice about the drug and dose in case of a known genotype? $\square$ Drug labelling (package insert)

$\square$ Registration authority

$\square$ Scientific literature

$\square$ Colleague

$\square$ Farmaceutisch Kompas

$\square$ Kennisbank / Informatorium medicamentorum

$\square$ Other ...

Q19: Were you aware that in the Netherlands dosing guidelines are available with information on the choice and dose of drugs based on the genotype of a patient?

Q20: Were you aware that in the Netherlands medication surveillance based on the genotype of a patient in incorporated in the automated drug dispensing systems?

$\square$ Yes

$\square$ No

Section 5: Worries toward PGx testing \& coverage of PGx testing

Q21: Do you think that your patient's unfavourable test results could have adverse psychological consequences on him and his family?

$\square$ Yes

$\square$ No

Q22: Are you worried that a PGx test might show there is no suitable drug for your patient? $(0=$ not worried $/ 3=$ very worried $)$ ?

\begin{tabular}{|l|l}
$\square$ Yes \\
\hline$\square$ No \\
\hline No opinion \\
\hline
\end{tabular}

$\square 0$

$\square 1$

$\square 2$

$\square 3$

Q23: Are you worried that a PGx test could reveal that your patient also has risk factors for another disease that he/she does not know about? $(0=$ not worried / 3 = very worried)?

\begin{tabular}{|l|l|}
$\square 0$ \\
\hline$\square 1$ \\
\hline$\square 2$ \\
\hline$\square 3$ \\
\hline
\end{tabular}

Q24: Are you worried that one of your patient's PGx test results could be passed to an unauthorized person? $(0=$ not worried $/ 3=$ very worried $)$

\begin{tabular}{|l|}
\hline$\square 0$ \\
\hline$\square 1$ \\
\hline$\square 2$ \\
\hline$\square 3$
\end{tabular}

Q25: Are you more concerned about the loss of privacy of a patient's genetic information from the results of pharmacogenetic tests than from the results of other laboratory or diagnostic tests?

$\square$ Yes

$\square$ No 
Q26: Among the following health professionals, which ones should have access to patients' pharmacogenetic information (select all that apply)

\begin{tabular}{|l|}
\hline$\square$ Physician \\
\hline$\square$ Pharmacist \\
\hline$\square$ Genetic counsellor \\
\hline$\square$ Clinical Chemist \\
\hline$\square$ Nurse practitioner \\
\hline$\square$ Psychologist \\
\hline$\square$ General nurse \\
\hline$\square$ Social worker \\
\hline$\square$ Dietician \\
\hline
\end{tabular}

Q27: Are you worried that a health insurance could obtain information about an individual's genotype based on the drug/dose prescribed? $(0=$ not worried / $3=$ very worried)

\begin{tabular}{|l|}
$\square 0$ \\
\hline$\square 1$ \\
\hline$\square 2$ \\
\hline$\square 3$
\end{tabular}

Q28: Do you believe that health insurers should provide full coverage for pharmacogenetic tests? $\square$ Always

$\square$ Sometimes

$\square$ Never 


\section{Supplementary document 2 - Results per question}

\begin{tabular}{|c|c|c|c|}
\hline Question & Answer & $\mathrm{N}$ & $\%$ \\
\hline \multicolumn{4}{|l|}{ Section 1: Baseline information } \\
\hline \multirow[t]{2}{*}{ Q1: What is your gender? } & $\square$ Male & 44 & 29.7 \\
\hline & $\square$ Female & 104 & 70.3 \\
\hline \multirow[t]{10}{*}{ Q2: What is your age? } & $\square 20$ & 4 & 2.7 \\
\hline & $\square 21$ & 11 & 7.4 \\
\hline & $\square 22$ & 15 & 10.1 \\
\hline & $\square 23$ & 30 & 20.3 \\
\hline & $\square 24$ & 35 & 23.6 \\
\hline & $\square 25$ & 31 & 20.9 \\
\hline & $\square 26$ & 15 & 10.1 \\
\hline & $\square 27$ & 1 & 0.7 \\
\hline & $\square 28$ & 4 & 2.7 \\
\hline & $\square 29$ & 2 & 1.4 \\
\hline \multirow[t]{3}{*}{ Q3: At which University do you currently follow your curriculum? } & $\square$ University of Groningen & 47 & 31.8 \\
\hline & $\square$ University of Utrecht & 101 & 68.2 \\
\hline & $\square$ Other & 0 & 0.0 \\
\hline \multirow[t]{5}{*}{ Q4: In which year of the program do you currently follow courses? } & $\square$ Second year & 1 & 0.7 \\
\hline & $\square$ Third year & 8 & 5.4 \\
\hline & $\square$ Fourth year & 18.2 & 18.2 \\
\hline & $\square$ Fifth year & 28.4 & 28.4 \\
\hline & $\square$ Sixth year & 47.3 & 47.3 \\
\hline \multirow{2}{*}{$\begin{array}{l}\text { Q5: Has PGx been part of any course that you have followed as part of } \\
\text { your curriculum }\end{array}$} & $\square$ Yes & 143 & 96.6 \\
\hline & $\square$ No & 5 & 3.4 \\
\hline \multicolumn{4}{|l|}{ Section 2: Belief and expectations towards PGx } \\
\hline \multirow{2}{*}{$\begin{array}{l}\text { Q6: Do you believe that a patient's genetic profile may influence } \\
\text { his/her response to drug therapy? }\end{array}$} & $\square$ Yes & 148 & 100.0 \\
\hline & $\square$ No & 0 & 0.0 \\
\hline \multirow{4}{*}{$\begin{array}{l}\text { Q7: Do you expect that pharmacogenetic testing will prevent your } \\
\text { patient from taking the wrong medicine (or the wrong dose)? }(0=\text { no } \\
\text { expectations... / } 3 \text { = very high expectations } \ldots)\end{array}$} & $\square 0$ & 5 & 3.4 \\
\hline & $\square 1$ & 15 & 10.1 \\
\hline & $\square 2$ & 73 & 49.3 \\
\hline & $\square 3$ & 55 & 37.2 \\
\hline \multirow{4}{*}{$\begin{array}{l}\text { Q8: Do you expect that pharmacogenetic testing will allow detecting } \\
\text { which drug (or which dose) will be more efficacious in your patient? }(0 \\
=\text { no expectations.../ } 3=\text { very high expectations } \ldots)\end{array}$} & $\square 0$ & 0 & 0.0 \\
\hline & $\square 1$ & 19 & 12.8 \\
\hline & $\square 2$ & 63 & 42.6 \\
\hline & $\square 3$ & 66 & 44.6 \\
\hline
\end{tabular}


Q9: Do you expect that pharmacogenetic testing will allow detecting which drug (or which dose) will cause less side effects in your patient? $(0=$ no expectations.../3 $=$ very high expectations ...)

\begin{tabular}{|l|l|l|}
\hline$\square 0$ & 6 & 4.1 \\
\hline$\square 1$ & 33 & 22.3 \\
\hline$\square 2$ & 66 & 44.6 \\
\hline$\square 3$ & 43 & 29.1 \\
\hline
\end{tabular}

Section 3: Attitude towards own ability to interpret PGx test results Q10: Would you feel qualified to receive your patient's pharmacogenetic testing results, interpret them and advise your patient on a treatment choice?

\begin{tabular}{|l|l|l|}
\hline$\square$ Yes & 41 & 27.7 \\
\hline $\begin{array}{l}\square \text { Yes, but after having had } \\
\text { training on the subject }\end{array}$ & 105 & 70.9 \\
\hline $\begin{array}{l}\square \text { No, this is not my } \\
\text { responsibility }\end{array}$ & 2 & 1.4 \\
\hline
\end{tabular}

Q11: Would you feel qualified to recommend pharmacogenetic testing to your patients if those tests could predict that a specific drug could be efficacious in their case?

\begin{tabular}{|l|l|l|}
\hline$\square$ Yes & 111 & 75.0 \\
\hline$\square$ No & 12 & 8.1 \\
\hline$\square$ Undecided & 25 & 16.9 \\
\hline
\end{tabular}

Q12: If a pharmacogenetic test revealed that the only available drug to treat your patient's disease is ineffective or leads to severe side effects, would you still advise your patient to take that medicine?

\begin{tabular}{|l|l|l|}
\hline$\square$ Yes & 7 & 4.7 \\
\hline $\begin{array}{l}\square \text { Yes, only if he/she had a } \\
\text { life-threatening disease }\end{array}$ & 95 & 64.2 \\
\hline$\square$ No & 46 & 31.1 \\
\hline
\end{tabular}

Q13: Would you feel qualified to recommend genetic testing to your patients if those tests could reveal which diseases are liable to affect them in the future

\begin{tabular}{|l|l|l|}
\hline$\square$ Yes & 31 & 20.9 \\
\hline $\begin{array}{l}\square \text { Yes, but only if that } \\
\text { disease could be treated }\end{array}$ & 34 & 23.0 \\
\hline$\square$ No & 46 & 31.1 \\
\hline$\square$ Undecided & 37 & 25.0 \\
\hline
\end{tabular}

Section 4: Access to and use of PGx information

Q14: Do you feel that you are adequately informed about the availability of genetic testing and its application in the context of drug therapy?

\begin{tabular}{|l|c|c|}
\hline$\square$ Yes & 19 & 87.2 \\
\hline$\square$ No & 129 & 87.2 \\
\hline
\end{tabular}

Q15: Would you obtain extra information on genetic testing and its application in the context of drug therapy?

(if "No" proceed to Q17)

\begin{tabular}{|l|l|l|}
\hline$\square$ Yes & 134 & 90.5 \\
\hline$\square$ No & 14 & 9.5 \\
\hline
\end{tabular}

Q16: Where would you obtain information on genetic testing and its application in the context of drug therapy? (select all that apply)

\begin{tabular}{|l|l|l|}
\hline $\begin{array}{l}\square \text { Drug labeling (package } \\
\text { insert) }\end{array}$ & 102 & 68.9 \\
\hline$\square$ Colleague & 75 & 50.7 \\
\hline $\begin{array}{l}\square \text { Post-academic education } \\
\text { and pharmacotherapeutic } \\
\text { meetings }\end{array}$ & 79 & 53.4 \\
\hline$\square$ Internet & 97 & 65.5 \\
\hline$\square$ Genetic testing laboratory & 68 & 45.9 \\
\hline$\square$ Other & 23 & 15.5 \\
\hline
\end{tabular}




\begin{tabular}{|c|c|c|c|c|}
\hline \multirow{20}{*}{$\begin{array}{l}\text { Q17: What level of evidence is of importance to } \\
\text { you in consideration of ordering a } \\
\text { pharmacogenetic test }\end{array}$} & \multirow{5}{*}{$\begin{array}{l}\text { authority } \\
\text { approval of } \\
\text { recommendation }\end{array}$} & $\square$ Very unimportant & 0 & 0.0 \\
\hline & & $\square$ Unimportant & 1 & 0.7 \\
\hline & & $\square$ Un-decided & 23 & 15.5 \\
\hline & & $\square$ Important & 75 & 50.7 \\
\hline & & $\square$ Very important & 49 & 33.1 \\
\hline & \multirow{5}{*}{$\begin{array}{l}\text { Speciality } \\
\text { guidelines }\end{array}$} & $\square$ Very unimportant & 0 & 0.0 \\
\hline & & $\square$ Unimportant & 0 & 0.0 \\
\hline & & $\square$ Un-decided & 13 & 8.8 \\
\hline & & $\square$ Important & 88 & 59.5 \\
\hline & & $\square$ Very important & 47 & 31.8 \\
\hline & \multirow[t]{5}{*}{ Scientific journal } & $\square$ Very unimportant & 0 & 0.0 \\
\hline & & $\square$ Unimportant & 1 & 0.7 \\
\hline & & $\square$ Un-decided & 25 & 16.9 \\
\hline & & $\square$ Important & 75 & 50.7 \\
\hline & & $\square$ Very important & 47 & 31.8 \\
\hline & \multirow{5}{*}{$\begin{array}{l}\text { Recommendation } \\
\text { or } \\
\text { experience of } \\
\text { thought } \\
\text { leaders or } \\
\text { respected } \\
\text { colleagues } \\
\end{array}$} & $\square$ Very unimportant & 0 & 0.0 \\
\hline & & $\square$ Unimportant & 12 & 8.1 \\
\hline & & $\square$ Un-decided & 67 & 45.3 \\
\hline & & $\square$ Important & 61 & 41.2 \\
\hline & & $\square$ Very important & 8 & 5.4 \\
\hline \multirow{7}{*}{\multicolumn{2}{|c|}{$\begin{array}{l}\text { Q18: Where would you obtain information to make a choice about the } \\
\text { drug and dose in case of a known genotype? }\end{array}$}} & $\begin{array}{l}\square \text { Drug labeling (package } \\
\text { insert) }\end{array}$ & 81 & 54.7 \\
\hline & & $\square$ Registration authority & 49 & 33.1 \\
\hline & & $\square$ Scientific literature & 115 & 77.7 \\
\hline & & $\square$ Colleague & 29 & 19.6 \\
\hline & & $\square$ Pharmaceutical Compass & 51 & 34.5 \\
\hline & & $\begin{array}{l}\text { Informatorium } \\
\text { Medicamentorum }\end{array}$ & 135 & 91.2 \\
\hline & & $\square$ Other ... & 1 & 0.7 \\
\hline \multirow{2}{*}{\multicolumn{2}{|c|}{$\begin{array}{l}\text { Q19: Were you aware that in the Netherlands dosing guidelines are } \\
\text { available with information on the choice and dose of drugs based on } \\
\text { the genotype of a patient? }\end{array}$}} & $\square$ Yes & 115 & 77.7 \\
\hline & & $\square \mathrm{No}$ & 33 & 22.3 \\
\hline \multirow{2}{*}{\multicolumn{2}{|c|}{$\begin{array}{l}\text { Q20: Were you aware that in the Netherlands medication surveillance } \\
\text { based on the genotype of a patient in incorporated in the automated } \\
\text { drug dispensing systems? }\end{array}$}} & $\square$ Yes & 35 & 23.6 \\
\hline & & $\square$ No & 113 & 76.4 \\
\hline \multicolumn{5}{|l|}{ Section 5: Worries toward PGx testing } \\
\hline \multirow{3}{*}{\multicolumn{2}{|c|}{$\begin{array}{l}\text { Q21: Do you think that your patient's unfavorable test results could } \\
\text { have adverse psychological consequences on him and his family? }\end{array}$}} & $\square$ Yes & 129 & 87.2 \\
\hline & & $\square$ No & 7 & 4.7 \\
\hline & & $\square$ No opinion & 12 & 8.1 \\
\hline
\end{tabular}


Q22: Are you worried that a PGx test might show there is no suitable drug for your patient? $(0=$ not worried $/ 3=$ very worried $)$ ?

\begin{tabular}{|l|l|l|}
\hline$\square 0$ & 40 & 27.0 \\
\hline$\square 1$ & 43 & 29.1 \\
\hline$\square 2$ & 43 & 29.1 \\
\hline$\square 3$ & 22 & 14.9 \\
\hline
\end{tabular}

Q23: Are you worried that a PGx test could reveal that your patient also has risk factors for another disease that he/she does not know about? $(0=$ not worried $/ 3=$ very worried $)$ ?

\begin{tabular}{|l|l|l|}
\hline$\square 0$ & 20 & 13.5 \\
\hline$\square 1$ & 43 & 29.1 \\
\hline$\square 2$ & 59 & 39.9 \\
\hline$\square 3$ & 26 & 17.6 \\
\hline
\end{tabular}

Q24: Are you worried that one of your patient's PGx test results could be passed to an unauthorized person? $(0=$ not worried $/ 3=$ very worried)

\begin{tabular}{|l|l|l|}
\hline$\square 0$ & 12 & 8.1 \\
\hline$\square 1$ & 30 & 20.3 \\
\hline$\square 2$ & 39 & 26.4 \\
\hline$\square 3$ & 67 & 45.3 \\
\hline
\end{tabular}

Q25: Are you more concerned about the loss of privacy of a patient's genetic information from the results of pharmacogenetic tests than from the results of other laboratory or diagnostic tests?

\begin{tabular}{|l|l|l|}
\hline$\square$ Yes & 34 & 23.0 \\
\hline$\square$ No & 114 & 77.0 \\
\hline
\end{tabular}

Q26: Among the following health professionals, which ones should have access to patients' pharmacogenetic information (select all that apply)

\begin{tabular}{|l|l|l|}
\hline$\square$ Physician & 145 & 98.0 \\
\hline$\square$ Pharmacist & 147 & 99.3 \\
\hline$\square$ Nurse practitioner & 25 & 16.9 \\
\hline$\square$ General nurse & 5 & 3.4 \\
\hline$\square$ Genetic counsellor & 116 & 78.4 \\
\hline$\square$ Clinical Chemist & 64 & 43.2 \\
\hline$\square$ Social worker & 2 & 1.4 \\
\hline$\square$ Psychologist & 13 & 8.8 \\
\hline$\square$ Dietician & 7 & 4.7 \\
\hline
\end{tabular}

Q27: Are you worried that a health insurance could obtain information about an individual's genotype based on the drug/dose prescribed? $(0=$ not worried / 3 = very worried)

\begin{tabular}{|l|l|l|}
\hline$\square 0$ & 2 & 1.4 \\
\hline$\square 1$ & 11 & 7.4 \\
\hline$\square 2$ & 36 & 24.3 \\
\hline$\square 3$ & 99 & 66.9 \\
\hline
\end{tabular}

Q28: Do you believe that health insurers should provide full coverage for pharmacogenetic tests?

\begin{tabular}{|l|l|l|}
\hline$\square$ Always & 32 & 21.6 \\
\hline$\square$ Sometimes & 116 & 78.4 \\
\hline$\square$ Never & 0 & 0.0 \\
\hline
\end{tabular}




\section{Supplementary table 3 - Comparison between pharmacy students and pharmacists}

\begin{tabular}{|c|c|c|c|c|c|}
\hline & \multicolumn{2}{|c|}{\begin{tabular}{|l} 
Pharmacy students \\
\end{tabular}} & \multicolumn{2}{|c|}{ Practicing pharmacists } & \multirow[b]{2}{*}{$\mathrm{p}$-value } \\
\hline & $\mathrm{N}$ & $\%$ & $\mathrm{~N}$ & $\%$ & \\
\hline \multicolumn{6}{|l|}{ Response } \\
\hline Yes & 148 & 18.0 & 667 & 18.8 & \multirow{2}{*}{$P=0.620$} \\
\hline No & 676 & 82.0 & 2883 & 81.2 & \\
\hline Total & 824 & 100.0 & 3550 & 100.0 & \\
\hline \multicolumn{6}{|l|}{ Q1: What is your gender? } \\
\hline Male & 44 & 29.7 & 305 & 45.7 & \multirow{2}{*}{$\mathrm{P}<0.001$} \\
\hline Female & 104 & 70.3 & 362 & 54.3 & \\
\hline Total & 148 & 100 & 667 & 100.0 & \\
\hline \multicolumn{6}{|l|}{ Q2: What is your age? } \\
\hline $20-29$ & 148 & 100.0 & 105 & 15.7 & \multirow{5}{*}{$\mathrm{P}<0.001$} \\
\hline $30-39$ & 0 & 0.0 & 209 & 31.3 & \\
\hline $40-49$ & 0 & 0.0 & 144 & 21.6 & \\
\hline $50-59$ & 0 & 0.0 & 158 & 23.7 & \\
\hline$\geq 60$ & 0 & 0.0 & 51 & 7.6 & \\
\hline Total & 148 & 100.0 & 667 & 100.0 & \\
\hline \multicolumn{6}{|c|}{ Q3: At which University do you currently follow your curriculum / did you follow your curriculum? } \\
\hline University of Groningen & 47 & 31.8 & 221 & 33.1 & \multirow{5}{*}{$\mathrm{P}<0.001$} \\
\hline University of Leiden & 0 & 0.0 & 38 & 5.7 & \\
\hline University of Utrecht & 101 & 68.2 & 537 & 53.5 & \\
\hline University of Amsterdam & 0 & 0.0 & 32 & 4.8 & \\
\hline Other & 0 & 0.0 & 19 & 2.8 & \\
\hline Total & 148 & 100.0 & 667 & 100.0 & \\
\hline \multicolumn{6}{|c|}{ Q5: Did you receive education on PGx during your curriculum } \\
\hline Yes & 143 & 96.6 & 265 & 60.3 & \multirow{2}{*}{$\mathrm{P}<0.001$} \\
\hline No & 5 & 3.4 & 402 & 39.7 & \\
\hline Total & 148 & 100.0 & 667 & 100.0 & \\
\hline \multicolumn{6}{|c|}{$\begin{array}{l}\text { Q10: Would you feel qualified to receive your patient's pharmacogenetic testing results, interpret them and advis } \\
\text { your patient on a treatment choice }\end{array}$} \\
\hline No & 2 & 1.4 & 45 & 6.7 & \multirow{3}{*}{$\mathrm{P}=0.038$} \\
\hline Yes & 41 & 27.7 & 180 & 27.0 & \\
\hline Yes, after training & 105 & 70.9 & 442 & 66.3 & \\
\hline Total & 148 & 100.0 & 667 & 100.0 & \\
\hline
\end{tabular}


Q11: Would you feel qualified to recommend pharmacogenetic testing to your patients if those tests could predict that a specific drug could be efficacious in their case

\begin{tabular}{|c|c|c|c|c|c|}
\hline No & 12 & 8.1 & 164 & 24.6 & \multirow{3}{*}{$\mathrm{P}<0.001$} \\
\hline Yes & 111 & 75.0 & 323 & 48.4 & \\
\hline Undecided & 25 & 16.9 & 180 & 27.0 & \\
\hline Total & 148 & 100.0 & 667 & 100.0 & \\
\hline
\end{tabular}

Q12: If a pharmacogenetic test revealed that the only available drug to treat your patient's disease is ineffective or leads to severe side effects, would you still advise your patient to take that medicine?

\begin{tabular}{|c|c|c|c|c|c|}
\hline No & 46 & 31.1 & 327 & 49.0 & \multirow{3}{*}{$\mathrm{P}<0.001$} \\
\hline Yes & 7 & 4.7 & 23 & 3.4 & \\
\hline $\begin{array}{l}\text { Yes, only if he/she had a life- } \\
\text { threatening disease }\end{array}$ & 95 & 64.2 & 317 & 47.5 & \\
\hline Total & 148 & 100.0 & 667 & 100.0 & \\
\hline
\end{tabular}

Q13: Would you feel qualified to recommend genetic testing to your patients if those tests could reveal which diseases are liable to affect them in the future

\begin{tabular}{|l|l|l|l|l|l|}
\hline No & 46 & 31.1 & 339 & 50.8 & \\
\cline { 1 - 5 } $\begin{array}{l}\text { Yes, but only if that disease could be } \\
\text { treated }\end{array}$ & 31 & 20.9 & 52 & 7.8 & $\mathrm{P}<0.001$ \\
\hline Undecided & 34 & 23.0 & 84 & 12.6 & \\
\hline Total & 37 & 25.0 & 192 & 28.8 & \\
\hline
\end{tabular}

Q15: Would you obtain extra information on genetic testing and its application in the context of drug therapy?

\begin{tabular}{|l|l|l|l|l|l|}
\cline { 1 - 4 } No & 14 & $9.5 \%$ & 409 & $61.3 \%$ & \multirow{2}{*}{$\mathrm{P}<0.001$} \\
\cline { 1 - 4 } Yes & 134 & $90.5 \%$ & 258 & $38.7 \%$ & \\
\cline { 1 - 5 } Total & 148 & 100.0 & 667 & 100.0 & \\
\hline
\end{tabular}

Q16: Where would you obtain information on genetic testing and its application in the context of drug therapy?

Drug labelling (package insert)

\begin{tabular}{|l|l|l|l|l|l|l|}
\hline No & 46 & 31.1 & 464 & 69.6 & \multirow{2}{*}{$\mathrm{P}<0.001$} \\
\hline Yes & 102 & 68.9 & 203 & 30.4 & \\
\hline Total & 148 & 100.0 & 667 & 100.0 & \\
\hline \multicolumn{7}{|l|}{} \\
\hline Colleague & 73 & 49.3 & 567 & 85.0 & \multirow{2}{*}{$\mathrm{P}<0.001$} \\
\hline No & 75 & 50.7 & 100 & 15.0 & \\
\hline Total & 148 & 100.0 & 667 & 100.0 & \\
\hline
\end{tabular}

Post-academic education and pharmacotherapeutic meetings

\begin{tabular}{|l|l|l|l|l|l|}
\hline No & 69 & 46.6 & 588 & 88.2 & \multirow{2}{*}{0.001} \\
\hline Yes & 79 & 534 & 79 & 11.8 & \\
\hline Total & 148 & 100.0 & 667 & 100.0 & \\
\hline
\end{tabular}




\begin{tabular}{|c|c|c|c|c|c|}
\hline \multicolumn{6}{|l|}{ Internet } \\
\hline No & 51 & 34.5 & 504 & 75.6 & \multirow{2}{*}{$\mathrm{P}<0.001$} \\
\hline Yes & 97 & 65.5 & 163 & 24.4 & \\
\hline Total & 148 & 100.0 & 667 & 100.0 & \\
\hline \multicolumn{6}{|c|}{ Genetic testing laboratory } \\
\hline No & 80 & 54.1 & 605 & 90.7 & \multirow{2}{*}{$\mathrm{P}<0.001$} \\
\hline Yes & 68 & 45.9 & 62 & 9.3 & \\
\hline Total & 148 & 100.0 & 667 & 100.0 & \\
\hline \multicolumn{6}{|l|}{ Other } \\
\hline No & 125 & 84.5 & 601 & 90.1 & \multirow{2}{*}{$P=0.046$} \\
\hline Yes & 23 & 15.5 & 66 & 9.9 & \\
\hline Total & 148 & 100.0 & 667 & 100.0 & \\
\hline \multicolumn{6}{|c|}{ Q18: Where do you obtain information to make a choice about the drug and dose in case of a known genotype } \\
\hline \multicolumn{6}{|c|}{ Scientific literature } \\
\hline No & 33 & 22.3 & 278 & 41.7 & \multirow{2}{*}{$\mathrm{P}<0.001$} \\
\hline Yes & 115 & 77.7 & 389 & 58.3 & \\
\hline Total & 148 & 100.0 & 667 & 100.0 & \\
\hline \multicolumn{6}{|l|}{ Other } \\
\hline No & 147 & 99.3 & 630 & 945 & \multirow{2}{*}{$P=0.011$} \\
\hline Yes & 1 & 0.7 & 37 & 5.5 & \\
\hline Total & 148 & 100.0 & 667 & 100.0 & \\
\hline \multicolumn{6}{|c|}{ Q20: Were you aware that in the Netherlands ... } \\
\hline \multicolumn{6}{|c|}{$\begin{array}{l}\text { medication surveillance based on the genotype of a patient in incorporated in the automated drug dispensing } \\
\text { systems? }\end{array}$} \\
\hline No & 113 & 76.4 & 231 & 34.6 & \multirow{2}{*}{$\mathrm{P}<0.001$} \\
\hline Yes & 35 & 23.6 & 436 & 65.4 & \\
\hline Total & 148 & 100.0 & 667 & 100.0 & \\
\hline \multicolumn{6}{|c|}{$\begin{array}{l}\text { Q21: Do you think that your patient's unfavourable test results could have adverse psychological consequences on } \\
\text { him and his family? }\end{array}$} \\
\hline No & 7 & 4.7 & 105 & 15.7 & \multirow{3}{*}{$\mathrm{P}<0.001$} \\
\hline Yes & 129 & 87.2 & 425 & 63.7 & \\
\hline No opinion & 12 & 8.1 & 137 & 2.5 & \\
\hline Total & 148 & 100.0 & 667 & 100.0 & \\
\hline
\end{tabular}


Q22: Are you worried that ...

A PGx test might show there is no suitable drug for your patient

\begin{tabular}{|c|c|c|c|c|c|}
\hline 0 & 40 & 27.0 & 268 & 40.2 & \multirow{4}{*}{$\mathrm{P}<0.001$} \\
\hline 1 & 43 & 29.1 & 210 & 31.5 & \\
\hline 2 & 43 & 29.1 & 150 & 22.5 & \\
\hline 3 & 22 & 14.9 & 39 & 5.8 & \\
\hline Total & 148 & 100.0 & 667 & 100.0 & \\
\hline
\end{tabular}

Q27: Which of the following health professionals should have access to the patient's PGx test results

Social worker

\begin{tabular}{|l|l|l|l|l|l|}
\hline No & 146 & 98.6 & 666 & 99.9 & \multirow{2}{*}{$\mathrm{P}=0.029$} \\
\cline { 1 - 5 } Yes & 2 & 1.4 & 1 & 0.1 & \\
\hline Total & 148 & 100.0 & 667 & 100.0 & \\
\hline
\end{tabular}




\section{Supplementary table 4: Result of the multivariate analysis of differences between pharmacy students and pharmacists}

To determine whether other covariates as age and gender could explain possible differences in answers found between the two groups the significant results of the univariate analysis were analysed using a multivariate model including age and gender. Questions with a dichotomous (YES/NO) answer model were analysed using a logistic regression model $(\mathrm{Q} 15,16,18 \& 20)$, whereas for questions with 3 or more answer options $(\mathrm{Q} 10,11,13,21)$ a multinomial regression model was used.

\section{Result of logistic regression analysis}

Q15: Would you obtain extra information on genetic testing and its application in the context of drug therapy?

\begin{tabular}{|l|l|r|}
\hline \multicolumn{2}{|l|}{ Odd's ratio (confidence interval) } & p-value \\
\hline Answer 1: Yes (vs. reference no) & $12,61(6,42-24,77)$ & $\mathbf{0 , 0 0 1}$ \\
\hline Cohort (students vs. pharmacist) & $0,60(0,43-0,83)$ & $\mathbf{0 , 0 0 2}$ \\
\hline Gender (female vs. male) & & 0,510 \\
\hline Age & $0,85(0,53-1,38)$ & 0,098 \\
\hline $30-39$ (vs. 20-29) & $0,64(0,38-1,08)$ & 0,123 \\
\hline $40-49$ (vs. 20-29) & $0,66(0,39-1,12)$ & 0,064 \\
\hline 50-59 (vs. 20-29) & $0,50(0,24-1,04)$ & \\
\hline $60-69$ (vs. $20-29)$ & & \\
\hline
\end{tabular}

Q16: Where do you obtain information on genetic testing and its application in the context of drug therapy - Drug labelling / package insert

\begin{tabular}{|l|l|r|}
\hline \multicolumn{2}{|l|}{ Odd's ratio (confidence interval) } & p-value \\
\hline Answer 1: Yes (vs. reference no) & $3,41(2,02-5,77)$ & $<, 108$ \\
\hline Cohort (students vs. pharmacist) & $0,77(0,56-1,06)$ & 0,080 \\
\hline Gender (female vs. male) & & $\mathbf{0 0 1}$ \\
\hline Age & $0,64(0,39-1,05)$ & 0,057 \\
\hline $30-39$ (vs. 20-29) & $0,51(0,30-0,89)$ & 0,130 \\
\hline $40-49$ (vs. 20-29) & $0,59(0,35-1,02)$ & 0,17 \\
\hline $50-59$ (vs. 20-29) & $0,56(0,27-1,18)$ & \\
\hline $60-69$ (vs. $20-29)$ & & \\
\hline
\end{tabular}

Q16: Where do you obtain information on genetic testing and its application in the context of drug therapy - Colleague

\begin{tabular}{|c|c|c|}
\hline & Odd's ratio (confidence interval) & p-value \\
\hline \multicolumn{3}{|l|}{ Answer 1: Yes (vs. reference no) } \\
\hline Cohort (students vs. pharmacist) & $3,28(1,88-5,70)$ & $<0,001$ \\
\hline Gender (female vs. male) & $0,94(0,64-1,38)$ & 0,768 \\
\hline \multicolumn{3}{|l|}{ Age } \\
\hline 30-39 (vs. 20-29) & $0,53(0,29-0,96)$ & $\mathbf{0 , 0 3 7}$ \\
\hline 40-49 (vs. 20-29) & $0,40(0,20-0,79)$ & 0,009 \\
\hline 50-59 (vs. 20-29) & $0,56(0,29-1,07)$ & 0,077 \\
\hline 60-69 (vs. 20-29) & $0,34(0,12-0,96)$ & 0,042 \\
\hline
\end{tabular}




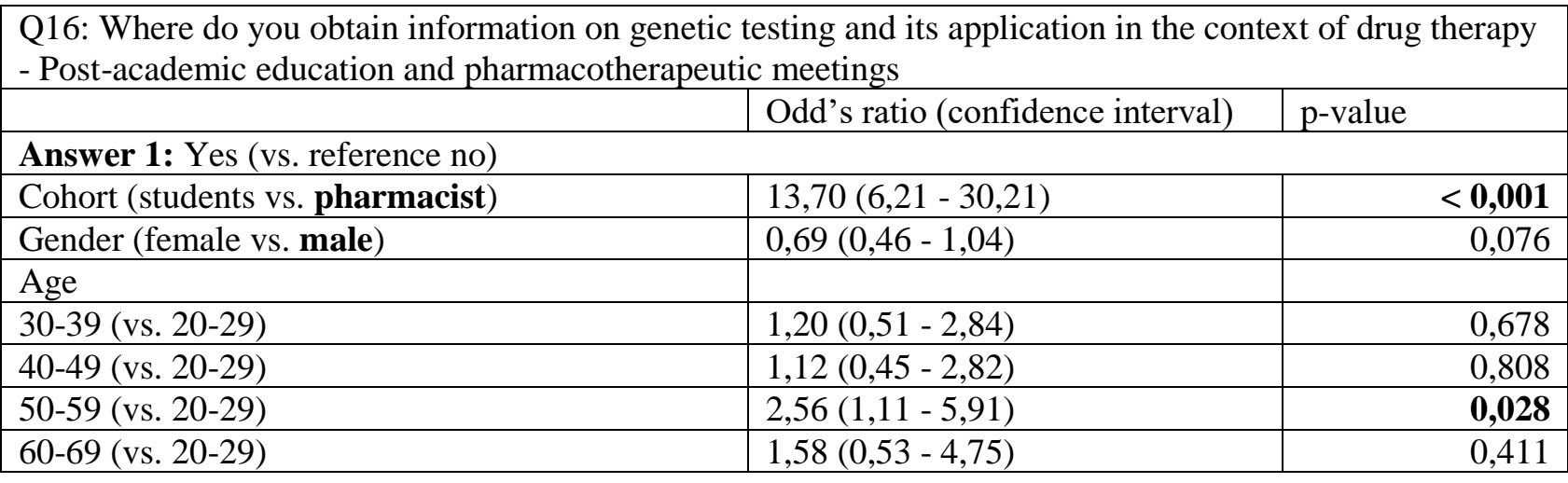

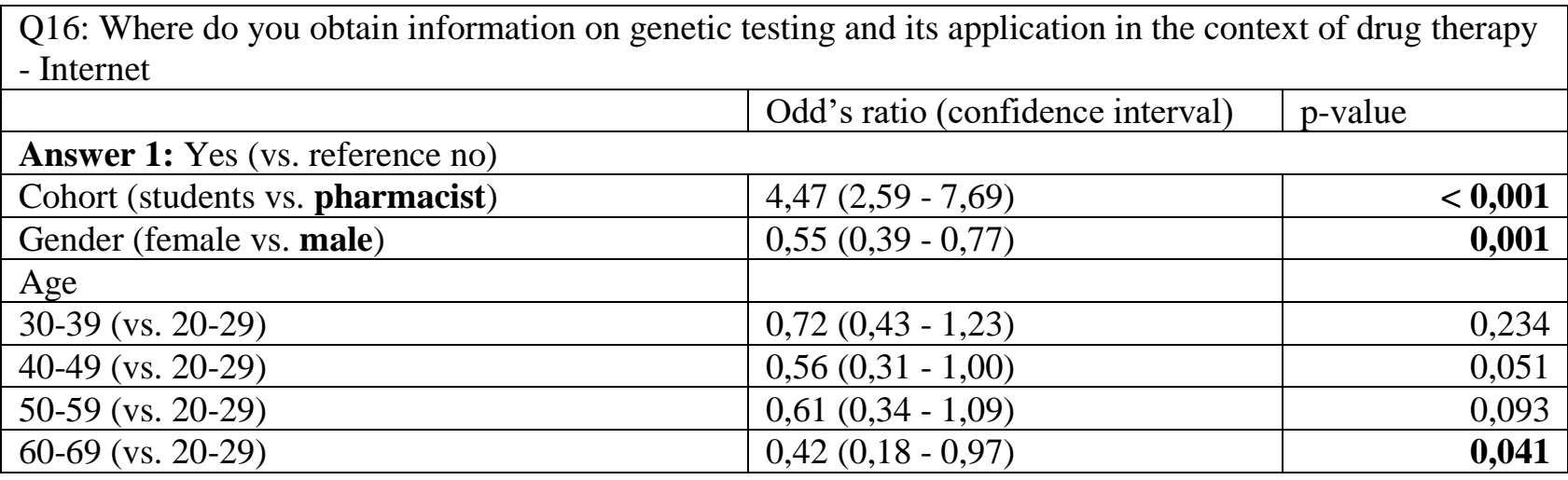

Q16: Where do you obtain information on genetic testing and its application in the context of drug therapy - Anders

\begin{tabular}{|c|c|c|}
\hline & Odd's ratio (confidence interval) & p-value \\
\hline \multicolumn{3}{|l|}{ Answer 1: Yes (vs. reference no) } \\
\hline Cohort (students vs. pharmacist) & $2,46(1,01-5,99)$ & $\mathbf{0 , 0 4 8}$ \\
\hline Gender (female vs. male) & $0,46(0,29-0,73)$ & $\mathbf{0 , 0 0 1}$ \\
\hline \multicolumn{3}{|l|}{ Age } \\
\hline 30-39 (vs. 20-29) & $2,29(0,97-5,42)$ & 0,059 \\
\hline 40-49 (vs. 20-29) & $1,09(0,41-2,90)$ & 0,861 \\
\hline 50-59 (vs. 20-29) & $0,61(0,22-1,74)$ & 0,358 \\
\hline 60-69 (vs. 20-29) & $1,01(0,30-3,44)$ & 0,988 \\
\hline
\end{tabular}

Q18: Where do you obtain information to make a choice about the drug and dose in case of a known genotype - Scientific Literature

\begin{tabular}{|c|c|c|}
\hline & Odd's ratio (confidence interval) & p-value \\
\hline \multicolumn{3}{|l|}{ Answer 1: Yes (vs. reference no) } \\
\hline Cohort (students vs. pharmacist) & $1,88(1,08-3,28)$ & $\mathbf{0 , 0 2 7}$ \\
\hline Gender (female vs. male) & $0,87(0,64-1,18)$ & 0,369 \\
\hline \multicolumn{3}{|l|}{ Age } \\
\hline 30-39 (vs. 20-29) & $0,91(0,56-1,49)$ & 0,709 \\
\hline $40-49$ (vs. 20-29) & $0,64(0,38-1,09)$ & 0,098 \\
\hline 50-59 (vs. 20-29) & $0,53(0,31-0,89)$ & $\mathbf{0 , 0 1 6}$ \\
\hline 60-69 (vs. 20-29) & $0,72(0,36-1,46)$ & 0,364 \\
\hline
\end{tabular}




\begin{tabular}{|c|c|c|}
\hline \multicolumn{3}{|c|}{$\begin{array}{l}\text { Q18: Where do you obtain information to make a choice about the drug and dose in case of a known } \\
\text { genotype - Other }\end{array}$} \\
\hline & Odd's ratio (confidence interval) & p-value \\
\hline \multicolumn{3}{|l|}{ Answer 1: Yes (vs. reference no) } \\
\hline Cohort (students vs. pharmacist) & $0,11(0,01-0,94)$ & 0,044 \\
\hline Gender (female vs. male) & $0,92(0,46-1,84)$ & 0,823 \\
\hline \multicolumn{3}{|l|}{ Age } \\
\hline 30-39 (vs. 20-29) & $1,08(0,40-2,95)$ & 0,882 \\
\hline 40-49 (vs. 20-29) & $0,58(0,17-1,98)$ & 0,390 \\
\hline 50-59 (vs. 20-29) & $1,20(0,41-3,47)$ & 0,741 \\
\hline 60-69 (vs. 20-29) & $0,65(0,12-3,46)$ & 0,609 \\
\hline
\end{tabular}

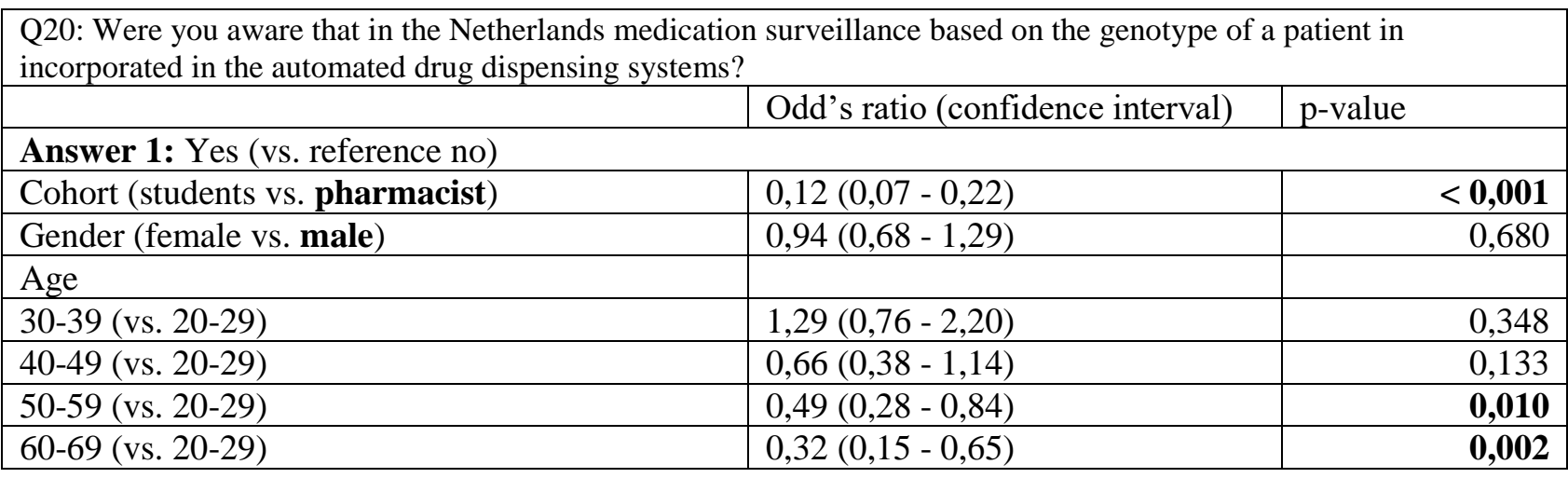

\section{Results of Multinomial regression}

Q10: Would you feel qualified to receive your patient's pharmacogenetic testing results, interpret them and advise your patient on a treatment choice? (Multinomial regression)

\begin{tabular}{|c|c|c|}
\hline & Odd's ratio (confidence interval) & p-value \\
\hline \multicolumn{3}{|l|}{ Answer 1: Yes (vs. reference no) } \\
\hline Cohort (students vs. pharmacist) & $2,59(0,47-14,26)$ & 0,274 \\
\hline Gender (female vs. male) & $0,27(0,13-0,55)$ & $<0,001$ \\
\hline \multicolumn{3}{|l|}{ Age } \\
\hline 30-39 (vs. 20-29) & $0,80(0,26-2,49)$ & 0,697 \\
\hline 40-49 (vs. 20-29) & $0,71(0,19-2,72)$ & 0,619 \\
\hline $50-59$ (vs. 20-29) & $0,10(0,03-0,34)$ & $<0,001$ \\
\hline 60-69 (vs. 20-29) & $0,10(0,02-0,43)$ & $\mathbf{0 , 0 0 2}$ \\
\hline \multicolumn{3}{|c|}{ Answer 2: Yes, after training (vs. reference no) } \\
\hline Cohort (students vs. pharmacist) & $3,97(0,75-21,07)$ & 0,106 \\
\hline Gender (female vs. male) & $0,56(0,29-1,10)$ & 0,090 \\
\hline \multicolumn{3}{|l|}{ Age } \\
\hline 30-39 (vs. 20-29) & $0,79(0,26-2,38)$ & 0,673 \\
\hline 40-49 (vs. 20-29) & $1,51(0,42-5,43)$ & 0,531 \\
\hline $50-59$ (vs. 20-29) & $0,40(0,14-1,16)$ & 0,092 \\
\hline 60-69 (vs. 20-29) & $0,34(0,09-1,26)$ & 0,106 \\
\hline
\end{tabular}




\begin{tabular}{|c|c|c|}
\hline & Odd's ratio (confidence interval) & p-value \\
\hline \multicolumn{3}{|l|}{ Answer 1: Yes (vs. reference no) } \\
\hline Cohort (students vs. pharmacist) & $5,25(2,47-11,16)$ & $<0,001$ \\
\hline Gender (female vs. male) & $0,57(0,39-0,85)$ & 0,006 \\
\hline \multicolumn{3}{|l|}{ Age } \\
\hline 30-39 (vs. 20-29) & $1,48(0,82-2,66)$ & 0,188 \\
\hline 40-49 (vs. 20-29) & $1,35(0,72-2,53)$ & 0,351 \\
\hline 50-59 (vs. 20-29) & $0,59(0,32-1,09)$ & 0,093 \\
\hline 60-69 (vs. 20-29) & $0,53(0,23-1,20)$ & 0,127 \\
\hline \multicolumn{3}{|c|}{ Answer 2: Undecided (vs. reference no) } \\
\hline Cohort (students vs. pharmacist) & $2,33(0,98-5,56)$ & 0,056 \\
\hline Gender (female vs. male) & $1,10(0,71-1,71)$ & 0,669 \\
\hline \multicolumn{3}{|l|}{ Age } \\
\hline 30-39 (vs. 20-29) & $1,46(0,75-2,86)$ & 0,267 \\
\hline 40-49 (vs. 20-29) & $1,40(0,68-2,87)$ & 0,363 \\
\hline $50-59$ (vs. 20-29) & $1,26(0,63-2,49)$ & 0,512 \\
\hline 60-69 (vs. 20-29) & $0,90(0,36-2,27)$ & 0,821 \\
\hline
\end{tabular}

Q12: If a pharmacogenetic test revealed that the only available drug to treat your patient's disease is ineffective or leads to severe side effects, would you still advise your patient to take that medicine?

\begin{tabular}{|c|c|c|}
\hline & Odd's ratio (confidence interval) & p-value \\
\hline \multicolumn{3}{|l|}{ Answer 1: Yes (vs. reference no) } \\
\hline Cohort (students vs. pharmacist) & $0,66(0,20-2,19)$ & 0,499 \\
\hline Gender (female vs. male) & $0,30(0,13-0,68)$ & $\mathbf{0 , 0 0 4}$ \\
\hline \multicolumn{3}{|l|}{ Age } \\
\hline 30-39 (vs. 20-29) & $0,31(0,09-1,01)$ & 0,051 \\
\hline 40-49 (vs. 20-29) & $0,37(0,12-1,19)$ & 0,096 \\
\hline 50-69 (vs. 20-29) & $0,05(0,01-0,25)$ & $<0,001$ \\
\hline \multicolumn{3}{|c|}{ Answer 2: Yes, only if he/she had a life-threatening disease (vs. reference no) } \\
\hline Cohort (students vs. pharmacist) & $0,88(0,50-1,54)$ & 0,646 \\
\hline Gender (female vs. male) & $1,42(1,04-1,93)$ & $\mathbf{0 , 0 2 5}$ \\
\hline \multicolumn{3}{|l|}{ Age } \\
\hline 30-39 (vs. 20-29) & $0,58(0,35-0,98)$ & 0,041 \\
\hline 40-49 (vs. 20-29) & $0,28(0,16-0,49)$ & $<0,001$ \\
\hline 50-69 (vs. 20-29) & $0,30(0,17-0,51)$ & $<0,001$ \\
\hline
\end{tabular}


Q13: Would you feel qualified to recommend genetic testing to your patients if those tests could reveal which diseases are liable to affect them in the future?

\begin{tabular}{|c|c|c|}
\hline & Odd's ratio (confidence interval) & p-value \\
\hline \multicolumn{3}{|l|}{ Answer 1: Yes (vs. reference no) } \\
\hline Cohort (students vs. pharmacist) & $3,64(1,63-8,12)$ & $\mathbf{0 , 0 0 2}$ \\
\hline Gender (female vs. male) & $0,30(0,18-0,51)$ & $<0,001$ \\
\hline \multicolumn{3}{|l|}{ Age } \\
\hline 30-39 (vs. 20-29) & $0,76(0,33-1,78)$ & 0,532 \\
\hline $40-49$ (vs. $20-29$ ) & $0,44(0,16-1,19)$ & 0,107 \\
\hline $50-59$ (vs. $20-29$ ) & $0,48(0,19-1,22)$ & 0,124 \\
\hline 60-69 (vs. 20-29) & $0,62(0,19-2,05)$ & 0,434 \\
\hline \multicolumn{3}{|c|}{ Answer 2: Yes, but only if that disease could be treated (vs. reference no) } \\
\hline Cohort (students vs. pharmacist) & $7,41(2,86-19,20)$ & $<0,001$ \\
\hline Gender (female vs. male) & $0,49(0,31-0,77)$ & $\mathbf{0 , 0 0 2}$ \\
\hline \multicolumn{3}{|l|}{ Age } \\
\hline 30-39 (vs. 20-29) & $2,28(0,88-5,92)$ & 0,090 \\
\hline $40-49$ (vs. 20-29) & $2,04(0,76-5,50)$ & 0,158 \\
\hline $50-59$ (vs. $20-29$ ) & $2,54(0,97-6,71)$ & 0,059 \\
\hline 60-69 (vs. 20-29) & $2,62(0,82-8,38)$ & 0,105 \\
\hline \multicolumn{3}{|c|}{ Answer 3: Undecided (vs. reference no) } \\
\hline Cohort (students vs. pharmacist) & $1,81(0,97-3,39)$ & 0,063 \\
\hline Gender (female vs. male) & $0,90(0,63-1,28)$ & 0,541 \\
\hline \multicolumn{3}{|l|}{ Age } \\
\hline 30-39 (vs. $20-29$ ) & $1,56(0,90-2,71)$ & 0,112 \\
\hline 40-49 (vs. 20-29) & $1,14(0,63-2,06)$ & 0,675 \\
\hline $50-59$ (vs. 20-29) & $1,19(0,65-2,18)$ & 0,567 \\
\hline 60-69 (vs. 20-29) & $1,15(0,50-2,66)$ & 0,737 \\
\hline
\end{tabular}




\begin{tabular}{|c|c|c|}
\hline & Odd's ratio (confidence interval) & p-value \\
\hline \multicolumn{3}{|l|}{ Answer 1: Yes (vs. reference no) } \\
\hline Cohort (students vs. pharmacist) & $2,92(1,08-7,89)$ & $\mathbf{0 , 0 3 4}$ \\
\hline Gender (female vs. male) & $1,41(0,91-2,17)$ & 0,121 \\
\hline \multicolumn{3}{|l|}{ Age } \\
\hline $30-39$ (vs. 20-29) & $0,49(0,24-1,02)$ & 0,058 \\
\hline $40-49$ (vs. 20-29) & $0,69(0,31-1,51)$ & 0,353 \\
\hline 50-59 (vs. 20-29) & $0,81(0,36-1,81)$ & 0,606 \\
\hline 60-69 (vs. 20-29) & $0,85(0,29-2,46)$ & 0,764 \\
\hline \multicolumn{3}{|c|}{ Answer 2: No opinion (vs. reference no) } \\
\hline Cohort (students vs. pharmacist) & $0,86(0,26-2,79)$ & 0,797 \\
\hline Gender (female vs. male) & $1,96(1,16-3,31)$ & $\mathbf{0 , 0 1 2}$ \\
\hline \multicolumn{3}{|l|}{ Age } \\
\hline $30-39$ (vs. $20-29$ ) & $0,52(0,22-1,21)$ & 0,131 \\
\hline $40-49$ (vs. 20-29) & $0,58(0,23-1,47)$ & 0,255 \\
\hline $50-59$ (vs. 20-29) & $1,02(0,41-2,57)$ & 0,962 \\
\hline $60-69$ (vs. 20-29) & $1,17(0,35-3,95)$ & 0,795 \\
\hline
\end{tabular}

